Article

\title{
Is the Web Marketing Mix Sustainable in China? The Mediation Effect of Dynamic Trust
}

\section{Yongrok Choi * and Jingwen Jin}

Department of International Trade, Inha University, Inharo100, Nam-gu, Incheon 402-751, Korea; E-Mail: clairejin84@gmail.com

* Author to whom correspondence should be addressed; E-Mail: yrchoi@inha.ac.kr; Tel.: +82-32-860-7760; Fax: +82-32-876-9328.

Academic Editor: Giuseppe Ioppolo

Received: 3 August 2015 / Accepted: 29 September 2015 / Published: 7 October 2015

\begin{abstract}
Trust plays an important role between companies and customers in the online shopping environment because of the anonymous transaction environment and the advantage of virtual property. The most rapidly developing trend in Chinese e-business may come from Guanxi, a Chinese term for social trust. In this study, we define Guanxi as the dynamic trust process in the social decisions or activities of the Chinese. With increasing global attention on the outstanding development of Chinese e-business, it would be worthwhile to analyze the dynamic trust process of social e-commerce customers in close combination with the social network. The statistical results obtained using structural equation modeling (SEM) show the importance of trust in a social e-commerce context. The direct positive relationship between the components of the web marketing mix and purchase intention is partially mediated by initial trust and ongoing trust, while initial trust only partially affects purchase intention through ongoing trust.
\end{abstract}

Keywords: Guanxi; social trust; web marketing mix; structural equation modeling; China; e-commerce

\section{Introduction}

In recent years, China has had significant achievements in all industries, especially in the field of e-commerce. China has the potential to become the biggest market for virtually everything, and e-commerce is no exception. E-commerce is surging, opening up many opportunities for ambitious 
companies if they pay close attention to the rapid development in the field. By the end of December 2014, the number of online shoppers had reached 649 million. China's e-commerce transaction volume increased to about 5.66 trillion yuan in the first half year of 2014, with year-on-year growth of $30.1 \%$. The deal size in the online retail market was about 1.1 trillion yuan, which marked an increase of $33.4 \%$ compared to the previous year, with semi-annual growth of $7.9 \%$. The deal size was equivalent to $8.4 \%$ of the total retail sales of social consumer goods in the first half of the year [1]. Six out of every 10 dollars spent online in Asia comes from China (see Table 1). China's e-commerce market presents immense opportunities to companies worldwide. Because of this potential market growth, many global leaders such as eBay in e-commerce and Facebook in social networking have participated in this market. Unfortunately, most of these global leaders were not successful in the Chinese market. Instead, strong local companies have made great progress in the e-commerce industry by utilizing locally unique factors in their businesses. One of the most salient features of this industry is the strategic partnership or ecosystem that exists for all related companies under one umbrella. This ecosystem is based on social networking with strong relationships among the companies, and it provides a multichannel platform for the companies.

Table 1. Estimated E-Commerce Sales in Asia for 2013-2015 (In Billions).

\begin{tabular}{llll}
\hline Country & $\mathbf{2 0 1 3}$ & $\mathbf{2 0 1 4}$ & $\mathbf{2 0 1 5}$ \\
\hline China & $\$ 181.62(50.2 \%)$ & $\$ 274.57(58.0 \%)$ & $\$ 358.59(62.2 \%)$ \\
Japan & $\$ 118.59(32.8 \%)$ & $\$ 127.06(26.8 \%)$ & $\$ 135.54(23.5 \%)$ \\
South Korea & $\$ 18.52(5.1 \%)$ & $\$ 20.24(4.3 \%)$ & $\$ 21.92(3.8 \%)$ \\
India & $\$ 16.32(4.5 \%)$ & $\$ 20.74(4.38 \%)$ & $\$ 25.65(4.4 \%)$ \\
Indonesia & $\$ 1.79(0.5 \%)$ & $\$ 2.60(0.55 \%)$ & $\$ 3.56(0.6 \%)$ \\
Other & $\$ 25.14(6.9 \%)$ & $\$ 28.16(5.9 \%)$ & $\$ 31.53(5.5 \%)$ \\
Total & $\$ 361.98(100 \%)$ & $\$ 473.37(100 \%)$ & $\$ 576.79(100 \%)$ \\
\hline
\end{tabular}

Source: GO-Globe [2].

Chinese customers are quickly adopting "multichannel" shopping behaviors, creating both opportunities and challenges for social e-commerce brands and companies, retailers, and e-commerce companies. Using the offline social network, which is called Guanxi (social trust in China), companies set up and modify the e-commerce ecosystem very quickly and effectively using multiple channels (see Figure 1). Social e-commerce brands such as Hey Juice are connected with grocery websites such as SF-Best, and they use Taobao as their marketing platform. This strategy combines all the reliable and easily accessible websites for their customers' benefit, thus helping them gain social trust. Companies that have been quick to capture the attention of these customers are already reaping significant benefits. If companies want to benefit from the rapid rise of online shopping in China, they need to understand the circumstances that make China's e-commerce environment unique.

Currently, usage and spending levels are increasing in every e-commerce category. However, certain categories are poised for dramatic new changes with the adding of the social element. If companies want to capture new opportunities in e-commerce, they must have a deeper understanding of the changing market demand and customize their strategies for new users. Only in this way can they participate in the new trend of the e-commerce ecosystem. Many relevant studies have been conducted in this field in mature markets and developed countries like the U.S. However, only a few empirical 
studies have been conducted in transient economies with a rapidly changing eco-systems such as that of China, in which the factors contributing to the consumers' online initial trust or online trust may differ from those in relatively mature markets. The unique national cultural background of a country might influence individual behaviors; thus, culture has some implications for trust development [3]. Since cultural homogeneity in Chinese society is stronger than those in most Western countries, social relations depend heavily on the level of trust. Ironically, trust is difficult to build in China. In China, the foundation of trust is based on social interpersonal experiences. Thus, compared to consumers in Western countries, the Chinese place high importance on mutual trust on the commercial transaction in a more dynamic sense.

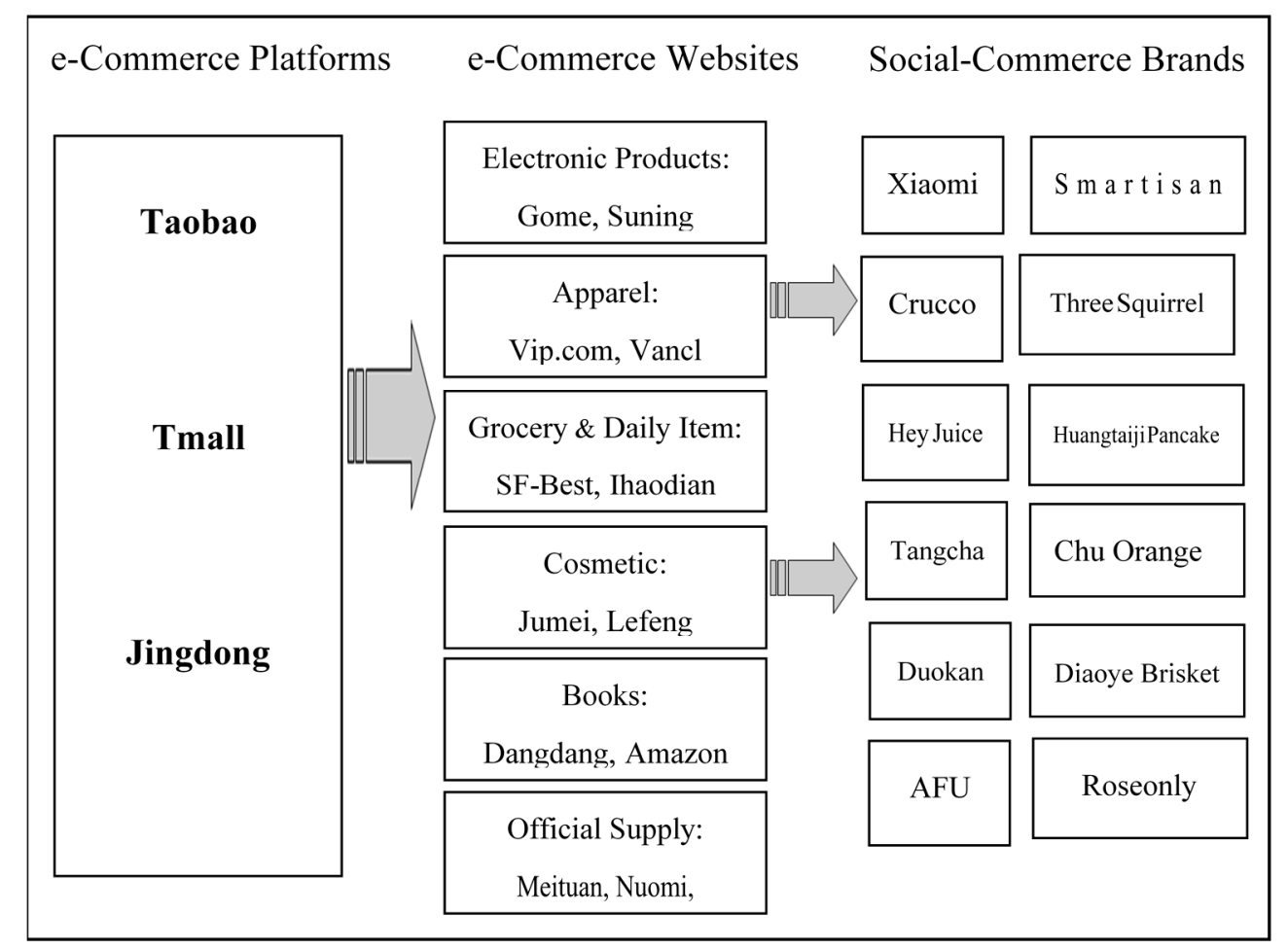

Figure 1. China's E-Commerce Ecosystem.

Therefore, for a better understanding of the Chinese market, it is essential to evaluate the role of these social interpersonal relationships (Guanxi) in e-commerce. In this study, social e-commerce is a subset of e-commerce. Social e-commerce involves online social media that support social interactions, and thus the building of trust. In this context, the relational marketing of the web marketing mix could be key to creating and maintaining Guanxi [4]. The process of building online trust is different from the offline trust-building process. In online transactions, customers deal with a graphical user interface instead of face-to-face communication. Before making the purchase decision, they judge the quality of the products by evaluating the web contents. Therefore, the characteristics of the websites are the most important factors for gaining customers' trust in e-commerce. Moreover, there is low switching cost online. Customers could switch from one website to another easily. Thus, websites should pay more attention to ongoing users instead of one-time users. Therefore, enhancing consumer trust in more dynamic terms becomes the most important issue for e-commerce companies who want to increase the purchase intention of customers. This study evaluates the effect of trust on 
consumer purchase intention in dynamic terms, as revealed by the web marketing mix strategies of the social networking platforms.

Several prior studies have treated trust as a mediator of the relationships between the characteristics of websites based on online environments and information technology [5]. Most prior researchers have considered trust as a whole, and used online trust as the mediator [6,7]. However, some researchers used initial trust as the mediator in their models [8]. Online trust refers to trust in e-commerce. Initial trust is defined as the first and the most important phase of building trust, while ongoing trust is defined as the transformation of initial trust over time. Since social e-commerce is based on the sustainable management of long-term relationships with the customers, online trust is defined as the combined dynamic process of initial and ongoing trust in this study $[9,10]$.

Once we decide to take the stepwise approach toward trust as the moderator of social e-commerce related to purchase intention, it would be appropriate to ask the following questions: does trust really function as a moderator in social e-commerce? If so, what factors affect trust, and how do they affect the dynamic process of trust building between initial and ongoing trust? This study aims to answer these questions related to the role of trust in the dynamic process of the web marketing mix in boosting the purchase intention using structural equation modeling.

The rest of this paper is organized as follows. Section 2 reviews the extant literature and proposes the hypotheses. Section 3 explains the methodology and data used in the empirical study. Section 4 presents the empirical results and related discussions. Section 5 presents the implications of the findings and concludes the paper.

\section{Theory and Hypotheses}

\subsection{Characteristics of Social E-Commerce}

The phrase "social e-commerce" was introduced by Yahoo.com in 2005, but the earliest academic analysis on social e-commerce was published in 2004 by James Surowiecki [11]. Surowiecki drafted the key rules and benefits of collective actions for exceptional decisions and for what he defined as collectively knowledgeable solutions that are based on the principals of opinion diversity, people's independence, decentralization, and aggregation [11]. Customers can cooperate and shop in an environment similar to social networking sites/services (SNS) combined with one or more online shopping mall partners; thus, relational knowledge is the key factor in social e-commerce [12-14]. Leitner and Grechenig defined social e-commerce using crowd sourcing (CS), consumer centric communities (CCC), and user generated content (UGC) (content perspective) [13], while Wang and Zhang introduced a framework of social e-commerce from four perspectives: people, business strategies, technology, and information (structural factors) [15]. However, the most important characteristic of social e-commerce is related to the dynamic process of transactions that is based on the collective knowledge and experiences of consumers. Thus, we could define social e-commerce as an online transaction based on a community that allows the use of the corporate experience of people, with intensive communication between potential and prior customers [12].

Thus, the core competence of social e-commerce is based on the capability to create and maintain relational marketing, which is different from the core competence of traditional marketing. Choi called 
this relational web-based marketing the "web marketing mix," which comprises the 4 Cs $[10,16]$. The 4 Ps - product, price, place, and promotion-constitute the most important theory in traditional marketing. In order to attract and manage more new customers, the quantity and quality of products, acceptable pricing, the efficiency of the marketing channel (place), and the diversity of sales promotion activities should be harmonized for profit maximization. However, in the e-commerce era, the traditional marketing mix cannot meet customers' needs. Therefore, the new trend of web marketing mix is required. The motivation of the web marketing mix is different from the basic motivation of traditional marketing. The goal or objectives of web marketing is to maximize not only the profit in the short-term and in accounting terms but also the invisible values such as the long-term loyalties, company image, brand values, new markets, and/or products for the future [10].

\subsection{Web Marketing Mix Hypotheses}

Unlike traditional marketing, the web marketing mix emphasizes the invisible value of purchase intention. In this context, purchase intention refers to the likelihood that customers will purchase a particular product. It is positively related to the final purchase probability, which would lead to direct economic benefits for the companies [17-19]. Purchase intention represents the consumers' subjective preferences for purchasing products and recommending products to their family and friends. Thus, the web marketing mix aims to drive purchase intention based on relational marketing on the Internet. In order to boost the consumers' purchase intention, websites should provide easier and more user-friendly access (communication) and online content that is very informative, amazing, and suitable for web surfing (contents); further, they should ensure short-term profits (commerce) and motivate the users to participate in the website to keep it alive and vivid in the long run (long-term effects) (community). These four web-marketing tools should be integrated into the websites to create and maintain the values. These four marketing strategies will be discussed in detail in the subsequent sub-sections.

\subsubsection{Communication}

The first factor in the web marketing mix is communication. Communication is defined as the availability and effectiveness of consumer support tools on a website. In today's fast-paced world, if the load time is longer than what the customers expect, even if there is important information, they would leave the site before the page loads. Consumers may feel that an online storefront is not easy to use if it cannot offer good navigation, helpful user guides, and a clear layout. Thus, the communication level of the sites is crucial for the initial entry to the site [16]. Ganguly [20] empirically proved that communication has a positive effect on purchase intention. Further, Davison and $\mathrm{Ou}$ [21] proposed that the effectiveness of communication tools has a positive effect on the customers' repeated purchase intention. According to Moorman et al. [22], active communication plays a crucial role in establishing a successful relationship between customers and companies, and it has a positive effect on customers' trust. Koufaris [23] concluded that communication has a positive effect on the customers' trust in social e-commerce in the long run. Thus, based on these arguments, we propose the following hypotheses: 
- H1: The degree of communication in a social e-commerce website has a positive effect on purchase intention.

- H2: The degree of communication in a social e-commerce website has a positive effect on initial trust.

- H3: The degree of communication in a social e-commerce website has a positive effect on ongoing trust.

\subsubsection{Contents}

Once customers easily and effectively access the websites, the contents of the sites (the second factor in web marketing) should arouse the customers' interest. In this context, contents refer to something that is very informative (informational content), amusing (design content), and suitable for web surfing (technology content) in a narrow sense [24]. Customers visit these websites for fun or for information. "For information" means that the available information is diverse, has depth, and is updated bilaterally. "For fun" means that the customers are interested in the content of the website or the products; i.e., they browse these sites for enjoyment. Ranganathan and Ganapathy empirically showed that the right information on a website could generate purchase intention [25]. Taylor and England tested whether the available information has a positive effect on customers' trust [26]. Moreover, Mithas and Jones empirically showed that relevant and updated information generates loyalty or ongoing trust [27]. Based on these arguments, we propose the following hypotheses:

- H4: The content of a social e-commerce website has a positive effect on purchase intention.

- H5: The content of a social e-commerce website has a positive effect on initial trust.

- H6: The content of a social e-commerce website has a positive effect on ongoing trust.

\subsubsection{Commerce}

Once the customer accesses the website with ease, and there is a good reason to re-visit for the content, the third factor in the web marketing mix comes into play, which is clearly intended to maximize the short-term profits through diverse types of commerce in the cyber space. Online customers always enjoy a price advantage derived from discounts, which could boost the purchase intention of these customers [28]. Moreover, Joung et al., claimed that low-priced products or services are one of the most important benefits of online shopping, and could increase the level of consumer trust in e-commerce [29]. Several prior studies emphasize the importance of commerce in purchase intention and trust building, because the commerce strategy on the website is the key factor for e-commerce $[4,13,16]$. Based on these arguments, we propose the following hypotheses:

- H7: The commerce strategy in a social e-commerce website has a positive effect on purchase intention.

- H8: The commerce strategy in a social e-commerce website has a positive effect on initial trust.

- H9: The commerce strategy in a social e-commerce website has a positive effect on ongoing trust. 


\subsubsection{Community}

Once a customer buys something on a website, the focus should be on the sustainable management of this customer in the long run. Community strategy forms the fourth factor of the web marketing mix. McMillan and Chavis (1986) define the sense of community as the members' sense of belonging, a feeling of self-importance with respect to one another [30]. Customers can develop a sense of community with other members through the high level of participation in social e-commerce websites. The availability of inter-customer communication enhances the perception of customers' trust in an online website; by sharing information or value-beliefs, customers are treated as a shared "family", and they can gain a sense of belonging [7,8]. Davison and Ou empirically showed that the interactions and social presence in a community have a positive effect on purchase intention [21]. In short, the sense of community implies, "once a customer, forever family." Based on these arguments, we propose the following hypotheses:

- H10: The sense of community in a social e-commerce website has a positive effect on purchase intention.

- H11: The sense of community in a social e-commerce website has a positive effect on initial trust.

- H12: The sense of community in a social e-commerce website has a positive effect on ongoing trust.

These web marketing mix strategies may or may not be effective in boosting the purchase intention because of the moderating governance of trust. Governance is defined as a workable mechanism for the sustainable performance of a collaborative network [4]. Thus, the role of trust in the web marketing mix should be examined in detail.

\subsection{The Intermediating Role of Trust on the Web Marketing Mix}

Several prior studies have shown the positive effect of trust on purchase intention [31-34]. Pavlou and Gefen [31] reported that customers' trust is a positive antecedent of a purchasing decision and a key factor that influences their purchase intentions. Jang et al. [32] found a significant relationship between trust and customers' purchase intentions. Kuan and Bock [33] concluded that customers' online trust has a positive effect on purchase intentions. However, most of these studies examined the role of either initial trust or online trust. However, trust is a more dynamic factor in social e-commerce than it is in any type of offline business because social e-commerce websites use SNS as their main platform to share information and experience; therefore, trust cannot be gained instantaneously. Especially in China, where ongoing trust (Guanxi) is a key element in online transactions, a stepwise approach is required to gain and build trust. Traditionally, the Chinese are prepared to transact only with people whom they already know well and with whom they have Guanxi [34]. Therefore, we need to examine the intermediating role of trust in social e-commerce by using the social network platform to boost the purchase intention more systematically over time. Here, we define Guanxi as mutual but subjective belief, with more dependable reliability, which represents a valuable sharing of thoughts/beliefs coming from a dynamic and sustainable process. 
Social network platforms such as Taobao give much more reliable and effective information, resulting in better initial trust. After gaining experience in the relationship, the customers' initial trust slowly evolves and transforms into ongoing trust. Thus, ongoing trust is more relevant to repeated individual activity that takes place over an extended period of time [35]. Especially in China, ongoing trust could be explained as Guanxi-the customer's positive expectation regarding a specific seller's conduct in the long run. Davison and $\mathrm{Ou}$ [21] showed that online initial trust has a positive effect on Guanxi in China. Based on these arguments, we propose the following hypotheses:

- H13: Customers' initial trust has a positive effect on ongoing trust.

- H14: Customers' initial trust has a positive effect on purchase intention.

- H15: Customers' ongoing trust has a positive effect on purchase intention.

Based on the proposed hypotheses, the conceptual model of this study is presented in Figure 2. Figure 2 shows that online trust as the intermediator could affect the stepwise approach to driving purchase intention. Therefore, we examine these hypotheses with the direct model (initial trust only) and the indirect model (initial and ongoing trust).

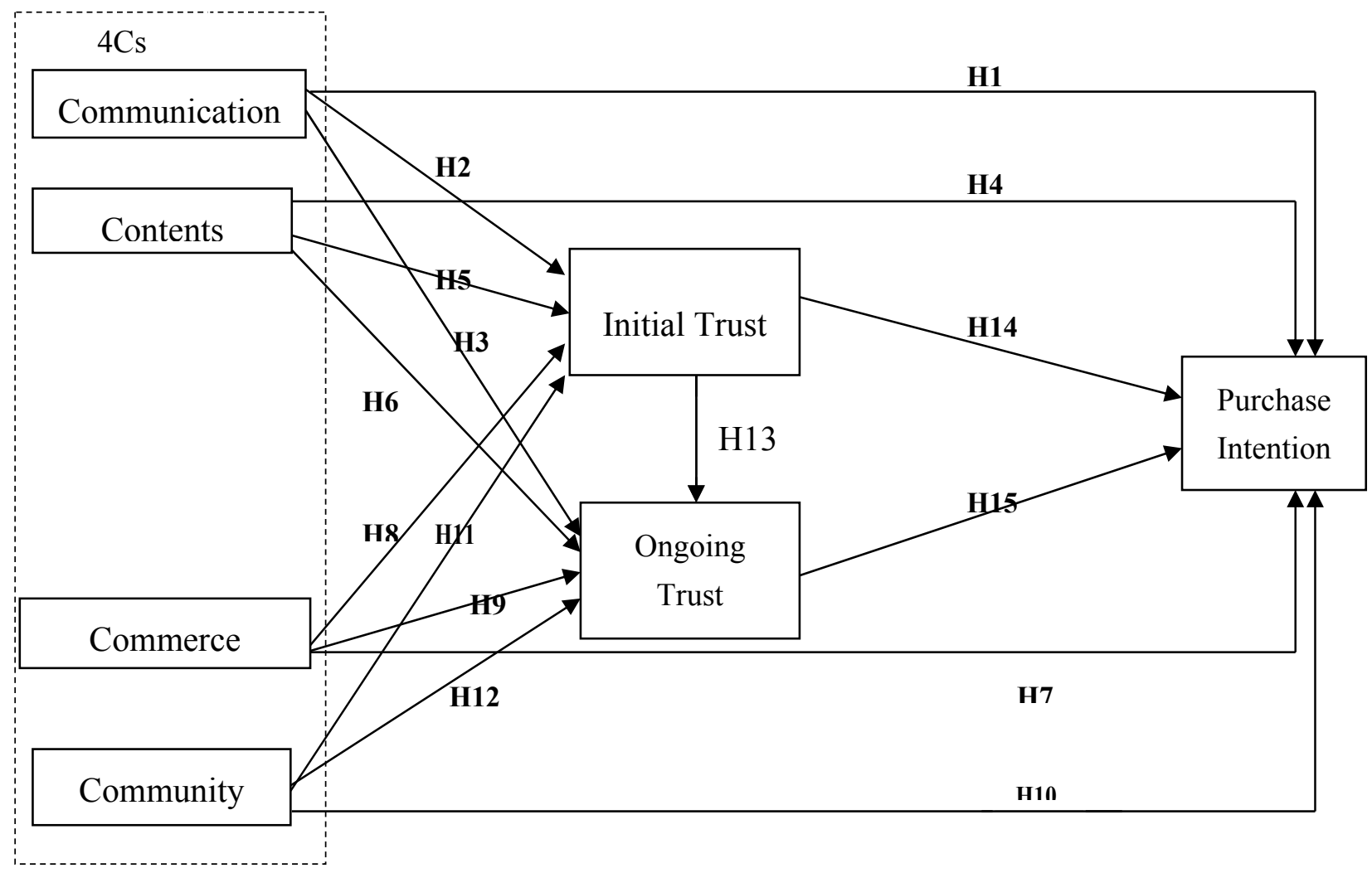

Figure 2. Research Framework.

\section{Methodology}

\subsection{Data}

For the empirical research, the data were collected through a questionnaire survey. First, a pilot study was conducted. Three experts with rich experience in corporate social responsibility (CSR) management were invited to evaluate the questionnaires. In addition, 20 senior users of social 
e-commerce were invited to complete the questionnaire as a pilot test. The questionnaire was modified based on the feedback received in the pilot stage. Then, full questionnaire surveys were conducted from January 15 to the end of March 2015. A total of 350 questionnaires were sent randomly to users of Chinese social e-commerce websites by e-mail or through messengers based on information retrieved from the Yellow Pages for various sectors and provinces. Based on the voluntarily provided answers to the questionnaire, 141 unique and usable responses were received (response rate of $40.28 \%$ ). In order to analyze the data descriptive statistics, the responses given to the questions were stored in an SPSS file. SPSS and AMOS were used to evaluate the strength of relationships between variables and answer the research objectives. The survey sample represents various sectors: college graduates account for $58 \%$ of the sample, while respondents who were graduates and above constitute $35 \%$ of the sample, implying that most of the customers $(93 \%)$ who are familiar with social e-commerce have a relatively good educational level. Table 2 presents the demographic characteristics of the respondents. All of the survey respondents reported to have more than one instance of user-experience with e-commerce.

To deal with the problem of non-response bias, we compared the early and late respondents, as recommended by Armstrong and Overton [36]. The 141 questionnaires were classified into two groups based on their finished time. An independent $t$-test was used to identify any differences between the answers of the early and late groups. The results indicated there were no significant differences in the various items of these two groups, which suggests that our sample is free from non-response bias.

Table 2. Demographic characteristics.

\begin{tabular}{lll}
\hline Characteristic & Items & Percentage \\
\hline \multirow{2}{*}{ Gender } & Male & $42 \%$ \\
\cline { 2 - 3 } & Female & $58 \%$ \\
\hline \multirow{4}{*}{ Age Range } & $0-25$ & $42 \%$ \\
\cline { 2 - 3 } & $26-30$ & $34 \%$ \\
\cline { 2 - 3 } & $31-40$ & $13 \%$ \\
\cline { 2 - 3 } & $41-50$ & $10 \%$ \\
\hline \multirow{4}{*}{ Education Level } & H1 and above & $1 \%$ \\
\cline { 2 - 3 } & High school or lower secondary education & $3 \%$ \\
\cline { 2 - 3 } & Colleges & $4 \%$ \\
\cline { 2 - 3 } & Undergraduate & $58 \%$ \\
\hline
\end{tabular}

\subsection{Measurement}

To measure all the observed variables in this study, we adopted well-established multiple-item 5-point Likert scales. These scales ranged from 1 ("strongly disagree") to 7 ("strongly agree"). The detailed measurement items are presented in Appendix Table A1.

\subsubsection{Web Marketing Mix Variables in the Model}

Following prior studies $[4,10,24]$, the hypotheses was tested empirically with regard to the degree to which the website enables the users to communicate with ease, the contents to retain their interest 
in the site, commerce to makes them consume the web services, subsequently, and relationship in the long-term to participate in the community. Thus, the web marketing mix variables (the inputs in the analysis) include the $4 \mathrm{Cs}$ : communication ( 4 items), contents (3 items), commerce (4 items), and community (4 items). These four dimensions were measured using a 7-point Likert scale ranging from "not considering it at all" (scale 1) to "perfectly agreed" (scale 7) in response to the questions about the degree of subjective perception with regard to the social e-commerce websites.

\subsubsection{Purchase Intention}

Spears and Singh (2004) defined purchase intention as an individual's conscious effort to purchase a trusted brand or product [19]. Purchase intention is defined as the level of consumers' subjective preferences for purchasing products and for recommending products to their family and friends. Before customers buy something, all of them have specific requirements in mind. Based on their needs, after browsing the related information, customer will filter, evaluate, and compare the information or products, and subsequently make a rational purchase decision. Pavlou and Genfen (2004) proved that purchase intention is one of the performances of trust [31]. Therefore, in this research, we consider purchase intention as the output of the model, measured by 4 items.

\subsubsection{Initial Trust and Ongoing Trust as Moderators}

Trust depends on a dynamic and sustainable process. Gan Yang (2013) empirically showed that initial trust has a direct and positive effect on ongoing trust [37]. It seems crucial to understand the dynamic process of trust over time, with a stepwise approach between initial and ongoing trust. Therefore, this study handles the first mediator of initial trust and the second of ongoing trust with 3 items each.

Structural equation modeling (SEM) was used to test the research hypotheses related to the latent variables. The SEM technique involves a multiple regression analysis, path analysis, and confirmatory factor test [38]. Some empirical analyses of sustainable behaviors include the following: [39,40]. The use of SEM to test mediation could overcome the problems of measurement error in the mediator variable score, which could result in difficulties related to modeling causality and possible reverse causality in hierarchical regression.

\section{Empirical Results}

\subsection{Reliability Test}

Our proposed model must be statistically reliable and valid. Reliability describes the overall consistency of a measure; the proposed method should show similar results when re-tested under the same conditions. For the reliability test, we use the widely known Cronbach's alpha coefficient, the corrected item-total correlation coefficient, and the construct reliability coefficient. These are the most commonly used criteria for measuring reliability [41]. As shown in Table 3, each measure is well above the suggested threshold of $0.7,0.5$, and 0.8 , respectively. These values are considered to be adequate for confirming a satisfactory level of reliability in this study. 
Table 3. Reliability test of the latent variables.

\begin{tabular}{ccccc}
\hline \multirow{2}{*}{ Latent Variables } & No. of Items & Cronbach's $\boldsymbol{\alpha}(>\mathbf{0 . 7})$ & Corrected Item-Total & Construct \\
\cline { 4 - 5 } & & & Correlation $(>\mathbf{0 . 5})$ & Reliability $(>\mathbf{0 . 8})$ \\
\hline Communication & 4 & 0.824 & $0.663-0.692$ & 0.825 \\
Contents & 3 & 0.855 & $0.633-0.736$ & 0.854 \\
Commerce & 4 & 0.805 & $0.632-0.796$ & 0.806 \\
Community & 4 & 0.834 & $0.675-0.724$ & 0.839 \\
Initial Trust & 3 & 0.849 & $0.695-0.748$ & 0.850 \\
Ongoing Trust & 3 & 0.890 & $0.743-0.780$ & 0.891 \\
Purchase Intention & 4 & 0.891 & $0.723-0.765$ & 0.895 \\
\hline
\end{tabular}

\subsection{Validity Test}

The validity of an assessment is the degree to which it measures what it is supposed to measure (the true information). The validity analysis includes both content and construct validity components. The content validity analysis tests the representativeness of the items in the questionnaire. There were no reports of misunderstanding during the pilot test. The interviewees stated that the items were easily understood, which indicates good content validity [41].

Confirmatory factor analysis (CFA) is one of the most effective tools to test construct validity. According to Campbell and Fiske [42], construct validity typically tests the extent to which data provide the following: (a) convergent validity, the extent to which different assessment methods show similar measurements of the same trait (i.e., the construct values, ideally, should be moderately high); (b) discriminant validity, the extent to which independent assessment methods show divergent measurements of different traits (ideally, these values should demonstrate minimal convergence).

As summarized by Choi and $\mathrm{Yu}$ [41], convergent validity occurs when (a) all the factor loadings are significantly over the 0.5 cut-off point; and (b) the average variance extracted (AVE) from the items by their respective constructs is greater than 0.5. Table 3 shows the results of the convergent validity measured using CFA. The measurement scale shows a strong convergent validity because all the factor loadings are significant and over 0.5, and the AVE of all the items is greater than 0.5 .

As Fornell and Larker (1981) suggested [43], the estimate of standardized factor loadings should be significantly over the 0.5 cut-off point. We evaluated the convergent reliability of constructs by average variance extracted (AVE). As shown in Table 4, the AVEs of all seven constructs are well above the critical value of 0.5 , indicating that these seven constructs capture more than $50 \%$ of the variance in their observable measures. Therefore, we can say that the convergent reliability of constructs is satisfactory.

Discriminant validity is achieved when the square root of the AVE for the constructs is greater than any of the corresponding inter-construct correlations. Table 5 shows that the square roots of the AVE of all the variables are greater than their inter-correlations, which supports the discriminant validity. 
Table 4. Convergent validity test on the measurement model.

\begin{tabular}{|c|c|c|c|c|}
\hline Variable & Items & SFL $^{a}$ & C. $\mathbf{R}^{\mathbf{b}}$ & $\mathrm{AVE}^{\mathrm{c}}$ \\
\hline \multirow{4}{*}{ Purchase Intention } & Purchase Intention 1 & 0.725 & - & \multirow{4}{*}{0.68} \\
\hline & Purchase Intention 2 & 0.761 & 9.883 & \\
\hline & Purchase Intention 3 & 0.782 & 9.985 & \\
\hline & Purchase Intention 4 & 0.711 & 9.293 & \\
\hline \multirow{4}{*}{ Communication } & communication1 & 0.689 & - & \multirow{4}{*}{0.50} \\
\hline & communication2 & 0.680 & 8.346 & \\
\hline & communication3 & 0.736 & 8.233 & \\
\hline & communication4 & 0.715 & 8.604 & \\
\hline \multirow{3}{*}{ Contents } & contents1 & 0.751 & - & \multirow{3}{*}{0.51} \\
\hline & contents 2 & 0.663 & 9.326 & \\
\hline & contents4 & 0.749 & 10.362 & \\
\hline \multirow{4}{*}{ Commerce } & commerce1 & 0.632 & - & \multirow{4}{*}{0.54} \\
\hline & commerce2 & 0.758 & 6.830 & \\
\hline & commerce 3 & 0.778 & 6.584 & \\
\hline & commerce4 & 0.762 & 6.696 & \\
\hline \multirow{4}{*}{ Community } & community1 & 0.734 & - & \multirow{4}{*}{0.56} \\
\hline & community2 & 0.755 & 8.893 & \\
\hline & community3 & 0.750 & 8.481 & \\
\hline & contents 3 & 0.714 & 8.588 & \\
\hline \multirow{3}{*}{ Initial Trust } & Initial Trust1 & 0.809 & - & \multirow{3}{*}{0.57} \\
\hline & Initial Trust2 & 0.711 & 9.373 & \\
\hline & Initial Trust3 & 0.755 & 10.980 & \\
\hline \multirow{3}{*}{ Ongoing Trust } & Ongoing Trust1 & 0.832 & - & \multirow{3}{*}{0.73} \\
\hline & Ongoing Trust2 & 0.886 & 8.124 & \\
\hline & Ongoing Trust3 & 0.854 & 9.563 & \\
\hline
\end{tabular}

${ }^{a} \mathrm{SFL}$ is an estimate of standardized factor loading; ${ }^{\mathbf{b}} \mathrm{C} . \mathrm{R}$ is the critical ratio; ${ }^{\mathbf{c}} \mathrm{AVE}$ is the average variance extracted.

Table 5. Discriminant validity test of the measurement model.

\begin{tabular}{llllllll}
\hline Construct Items & Cmm & Cmc & Cts & Cen & Itr & Otr & Pin \\
\hline Community (Cmm) & $0.748^{\mathrm{a}}$ & & & & & & \\
Commerce (Cmc) & 0.531 & $0.735^{\mathrm{a}}$ & & & & & \\
Contents (Cts) & 0.606 & 0.525 & $0.714^{\mathrm{a}}$ & & & & \\
Communication (Ccn) & 0.494 & 0.485 & 0.537 & $0.707^{\mathrm{a}}$ & & & \\
Initial Trust (Itr) & 0.613 & 0.564 & 0.623 & 0.546 & $0.755^{\mathrm{a}}$ & & \\
Ongoing Trust (Otr) & 0.679 & 0.607 & 0.628 & 0.527 & 0.760 & $0.854^{\mathrm{a}}$ & \\
Purchase Intention (Pin) & 0.713 & 0.617 & 0.635 & 0.546 & 0.798 & 0.764 & $0.822^{\mathrm{a}}$ \\
\hline
\end{tabular}

${ }^{a}$ The square root of the AVE as a criteria of the cutting point for correlation.

The goodness of fit of a statistical model represents how well it fits a set of variables. Measures of goodness of fit typically describe the discrepancy between observed values and the expected values under the model in questionnaire. Such measures can be used in statistical hypothesis testing of whether two samples are drawn from identical distributions, or of whether outcome frequencies follow a specified distribution. In the variance analysis, one of the components into which the variances are partitioned may be a lack-of-fit sum of squares. For testing the model fit, we also have used a number of goodness-of-fit indices recommended by many researchers; we evaluate the fit of the measurement 
model using indices such as (1) a normalized Chi-square $\left(\frac{X^{2}}{d f}\right) ;(2)$ goodness-of-fit (GFI); (3) root mean square error of approximation (RMSEA); (4) comparative fit index (CFI), and (5) incremental fit index (IFI) [44]. As shown in Table 6, all of the diverse goodness-of-fit indices were higher than the recommended criteria. Thus, the goodness-of-fit of the measurement model is acceptable.

Table 6. Goodness-of-fit test results.

\begin{tabular}{|c|c|c|c|}
\hline Indices & Recommended & Direct Model & Mediation Model \\
\hline$\frac{X^{2}}{d f}$ & $<5.0[44]$ & 1.672 & 1.978 \\
\hline GFI & $>0.8[41]$ & 0.826 & 0.829 \\
\hline RMSEA & $<0.10[41]$ & 0.084 & 0.069 \\
\hline $\mathrm{CFI}$ & \multirow{2}{*}{$>0.9[41]$} & 0.901 & 0.929 \\
\hline IFI & & 0.902 & 0.930 \\
\hline
\end{tabular}

As our data are all self-reported data, common method variance could exist. To address this issue, several procedural and statistical remedies were employed. First, the cover letter of the questionnaire assured the respondents that their answers would be anonymous, and that there was no right or wrong answers to any question. Second, we used Harman's one-factor test via CFA by specifying a hypothesized method factor as the underlying driver of all of the indicators. The results revealed that the fit of the single-factor model was extremely unsatisfactory, indicating that common method variance is not the major source of the variations in the items [41].

\subsection{Hypotheses Tests}

After confirming the reliability and validity of the questionnaire items, we tested the research hypotheses. The maximum likelihood estimation method was used for the hypotheses testing using the SEM. The empirical findings of the first stage of the direct model (without considering trust as the moderator) are shown in Figure 3.

In the direct model that involves the $4 \mathrm{Cs}$ (communication, contents, commerce, and community) and purchase intention, the results show that the 4 Cs have a positive impact on customers' purchase intention. Thus, $\mathrm{H} 1$ is supported $(p<0.001)$. That is, a higher level of communication in social e-commerce websites was associated with higher purchase intention. Further, H4 is supported $(p<0.01)$. Therefore, the content of social e-commerce websites is strongly and positively correlated with customers' purchase intention. Moreover, the data support H7 $(p<0.01)$. The commerce strategy in a social e-commerce website motivates the customers' purchase intention. The data show that the customers' sense of community can enhance their purchase intention $(p<0.001)$. H10 is also supported. Thus, an active community is an increasingly important way of boosting purchase intention. 


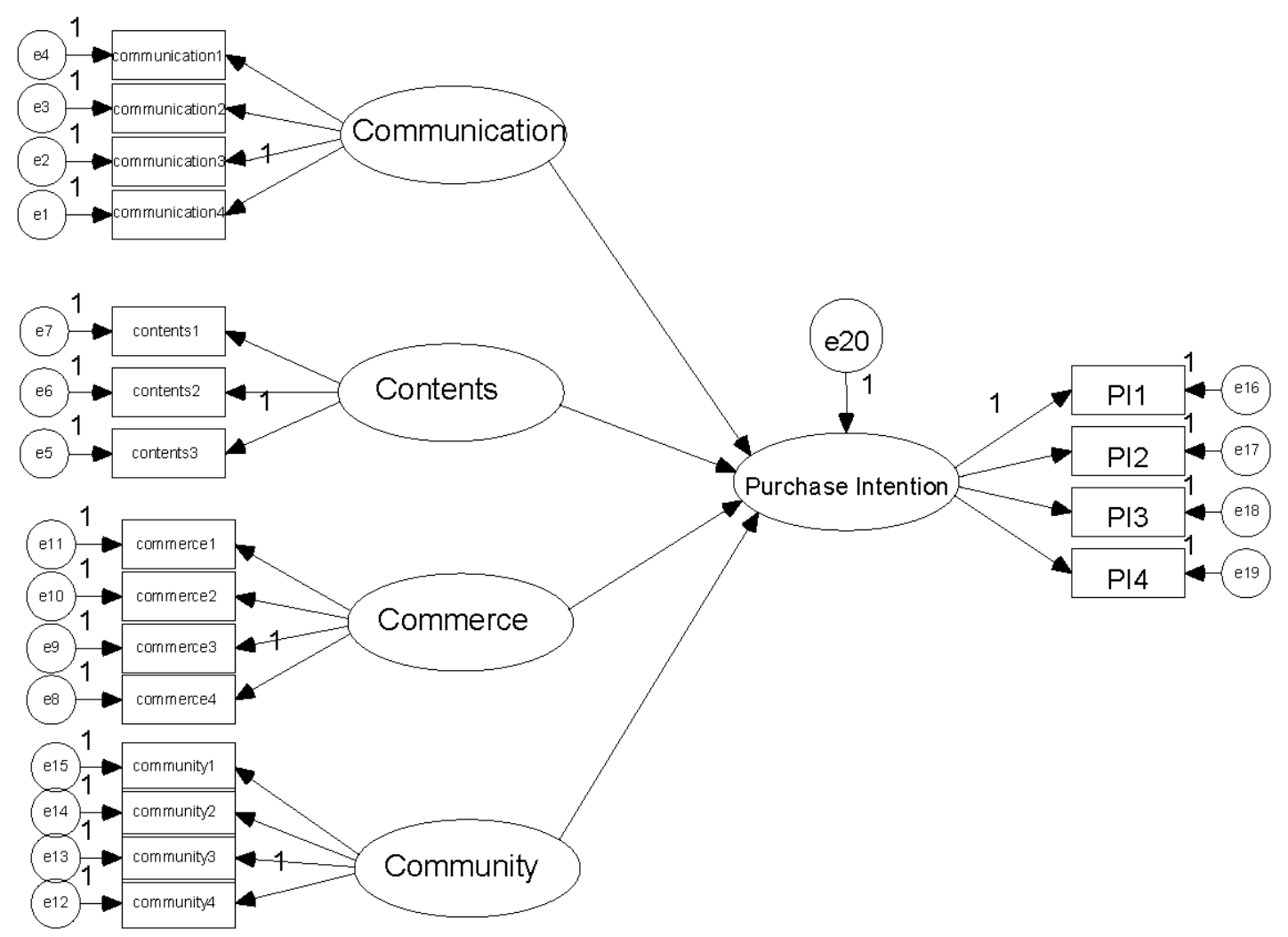

Figure 3. Results of the direct structural model.

For testing the mediating effect of initial trust and ongoing trust, the relationships among the variables should satisfy all of the conditions suggested by Baron and Kenny [45]: (1) the independent variable should influence the dependent variable significantly; (2) the independent variable should influence the mediator significantly; (3) the mediator must influence the dependent variable significantly; and (4) the impact of the independent variable on the dependent variable must diminish after controlling for the effects of the mediator. If any of these conditions are not satisfied, there is no mediation. If all of these conditions are satisfied, and the influence of the independent variable becomes non-significant in the presence of the mediator, the effects of the independent variable are said to be "completely" or "fully" mediated by the mediator. If all the conditions are satisfied while the influence of the independent variable remains significant in the presence of the mediator, the effects of the independent variable are said to be "partially" mediated $[41,46]$.

We run the indirect model of the relationship between the web marketing mix and purchase intention with the stepwise moderators of trust. The results show that the $4 \mathrm{Cs}$ have a direct positive effect on purchase intention at the $99 \%$ significance level $(p<0.001)$; therefore, condition (1) is supported. Condition (2) is supported by H2-H12. However, in the mediation model, the mediator condition (3) of initial trust is not satisfied because H14 is rejected. Therefore, initial trust is not a direct mediator between the $4 \mathrm{Cs}$ and purchase intention. However, H15 is supported, and condition (3) of ongoing trust is satisfied.

To examine condition (4), we compare the results of the direct model and the mediation model in Figure 4. We find that the $4 \mathrm{Cs}$ do not have a significant influence on purchase intention $(p>0.1)$, except "Commerce" (H3), which has a significant influence $(p<0.01)$ in the mediation model. However, with the inclusion of the direct model, the standard coefficient of commerce on purchase 
intention decreased from 0.42 to $0.13(\triangle=0.29)$. This implies that the relationship between the $4 \mathrm{Cs}$ and purchase intention is partially mediated by ongoing trust. Thus, ongoing trust could be an important factor in enhancing purchase intention in social e-commerce websites. Although initial trust is not the direct mediator, H13 is accepted, which indicates that initial trust could be regarded as an indirect mediator of purchase intention, only through ongoing trust.

Compared to the standard coefficients in the mediation model, we find that the web marketing mix has a stronger effect on initial trust rather than ongoing trust, because the standard coefficient of $\mathrm{H} 2$ $\left(0.52^{* * *}\right)$ is higher than the standard coefficient of $\mathrm{H} 3\left(0.32^{* *}\right)$; the standard coefficient of $\mathrm{H} 5$ $\left(0.46^{* * *}\right)$ is higher than the standard coefficient of H6 $\left(0.28^{* *}\right)$; the standard coefficient of H8 $(0.63 * * *)$ is higher than the standard coefficient of $\mathrm{H} 9\left(0.48^{* *}\right)$; and the standard coefficient of $\mathrm{H} 11$ $(0.72 * * *)$ is higher than the standard coefficient of $\mathrm{H} 12\left(0.54^{* *}\right)$. These results indicate that initial trust is an indispensable variable that connects the $4 \mathrm{Cs}$ and ongoing trust. Moreover, we find that the standard coefficients of community with initial trust and ongoing trust are higher than the others; thus, community is the most import construct for social e-commerce websites. Therefore, web-marketing companies should focus on enhancing the performance of the community construct in e-commerce.

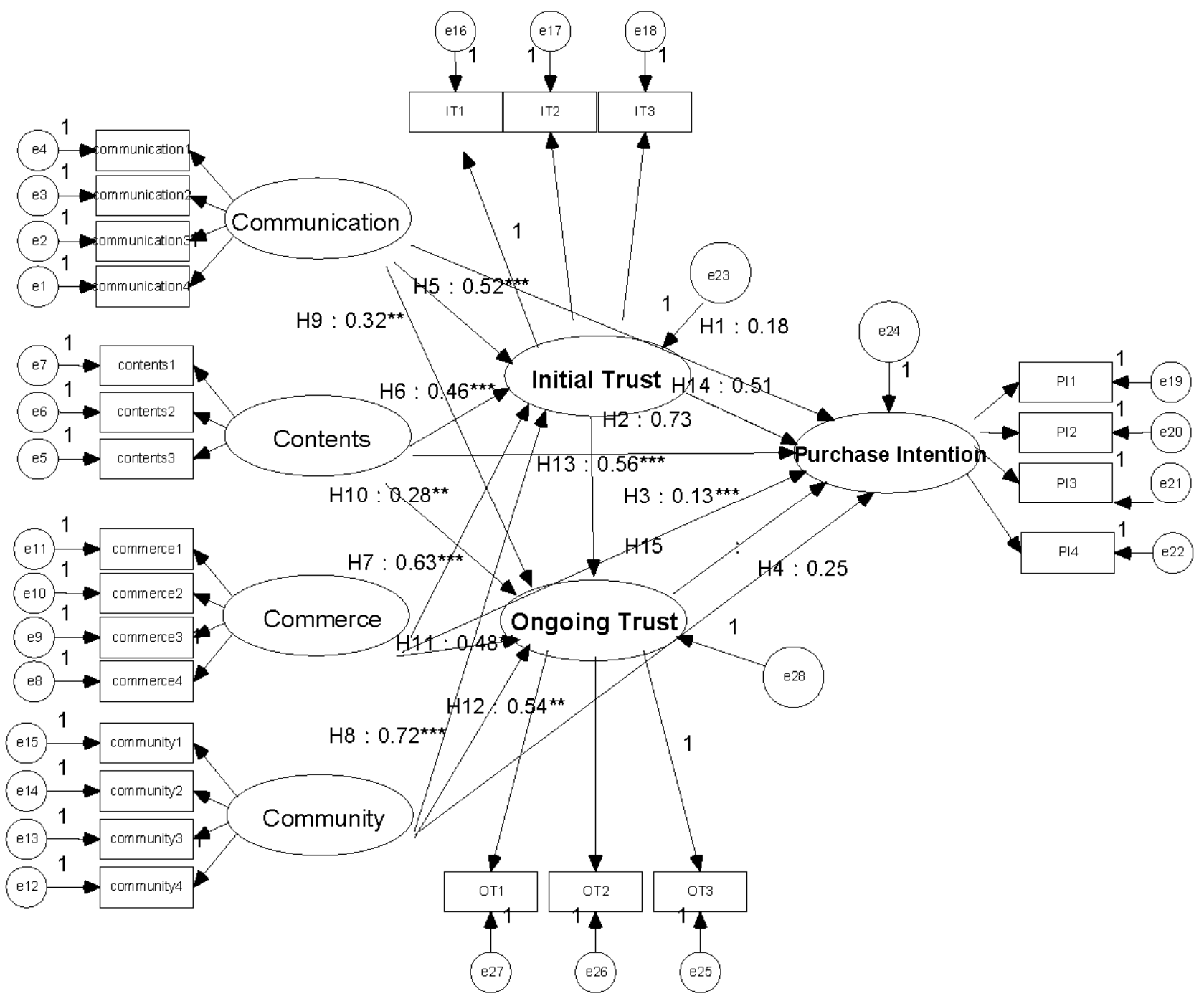

Figure 4. Results of the indirect structural model. 


\section{Discussion}

This study examined the influence of dynamic trust on social e-commerce based on the web marketing mix theory. In China, the local competitors with cultural-friendly web companies based on social e-platforms gain much more effective initial and ongoing trust, compared to the global leaders such as eBay and Facebook. The empirical results show that the issue of website dynamic trust is one of the most critical obstacles related to online transactions in social e-commerce. Over the past 10 years, many researchers have reported that trust is crucial for e-commerce; however, only a few of them noticed that trust is a kind of dynamic process. Customers' trust constantly transforms during the different stages of a transaction. Therefore, we classified trust as initial trust and ongoing trust based on perspectives of sustainability. In order to ensure successful performance, websites need to have a deeper understanding of how initial trust and ongoing trust are developed and how they affect purchase intention. We showed that ongoing trust significantly and positively affects purchase intention much more than initial trust does. This means that despite the best web marketing strategies of advanced global companies, if they are not agile enough to adopt the changing trends of the e-commerce ecosystem, they cannot maintain or build ongoing trust. This is why most global companies could not gain a competitive edge in the local markets of transient economies such as Korea and China.

The concept of Guanxi is an essential business concept in China; thus, the promotional strategies for ongoing trust are quite important. Our results imply that initial trust is not very effective compared to ongoing trust; thus, building ongoing trust should be emphasized. The web marketing mix components are effective only when they are strengthened by ongoing trust. There are two types of Guanxi: connection-based and money-based relationships. Money-based Guanxi may increase the initial trust, while the relationship-based Guanxi-ChangQiXinRen (ongoing trust) - is a much more important factor in creating value for all the ecosystem participants (including customers) compared to the other marketing tools such as price and quantity. What makes it difficult to do business in China is not the lack of Guanxi (as initial trust), but the lack of ongoing trust.

Alibaba.com provides a good benchmarking case in building ongoing trust. In the beginning, trust and credit issues between the sellers and customers were the biggest obstacles for Alibaba. However, Alibaba did not try to address the trust issue until its users reached 1 million. In 2002, Alibaba launched a strategy to address trust risk management and to create values from this trust risk by introducing "TrustPass." It serves to provide transparency regarding the identity and legitimacy of suppliers on Alibaba. In order to become a TrustPass member, a supplier must first be verified and authenticated by a third-party credit agency before their membership is approved [47]. The annual membership fee for this service is \$250 USD. This scheme resulted in a new source of sustainable revenue and led to great success, as shown by the hyper-rocketing sales volume. Alibaba's successful case educated the Chinese government and led to changes in the regulatory platform. Initially, there were not many regulations related to trust in the context of e-commerce; however, the central government understood the necessity for the easier control and management for the qualification of companies through the TrustPass program. Many local governments provided public funding and cooperated with Alibaba to subsidize small local companies to allow them to get Alibaba's TrustPass.

Even if the growth rate of northeast Asian countries such as China and Korea are still leading the global economy, their sustainable performance cannot be guaranteed to continue over time. Thus, 
priority should be given to the sustainable strategies from the perspective of the overall performance of the e-commerce ecosystem. However, because of the complexity of a sustainable operation for a collaborative ecosystem, it is especially difficult to visualize the performance of these sustainable strategies and practices. Even so, if the government fails to market-orient implementation of the e-business policies, it may lose the trust of the public and then finally over-supply or shortages may bring worse market performance. This paper strongly emphasizes the role of ongoing trust in e-business promotion policies.

\section{Conclusions}

This study evokes the importance of creating a new paradigm of field- and performance-oriented strategies. The issues of dynamic trust presented in this study emphasize the urgent need to address the missing link in the collaborative network from the procedural perspective. Thus, the intermediary role of initial and ongoing trust in addressing this missing link cannot be emphasized enough, especially in transient economies such as China and Korea [48].

\section{Acknowledgments}

The National Research Foundation of Korea Grant funded by the Korean Government (NRF-2014S1A5B1011422) and Inha University Research Grant supported this work.

\section{Author Contributions}

The authors contributed equally to this work.

\section{Conflicts of Interest}

The authors declare no conflict of interest.

\section{Appendix}

Table A1. Measurement items for latent variables.

\begin{tabular}{|c|c|c|c|c|c|c|c|}
\hline \multirow[t]{2}{*}{ Questions } & \multicolumn{7}{|c|}{$\begin{array}{l}\text { Strongly Disagree } \\
\rightarrow \text { Strongly Agree }\end{array}$} \\
\hline & 1 & 2 & 3 & 4 & 5 & 6 & 7 \\
\hline \multicolumn{8}{|l|}{ 1. Questions about Communication } \\
\hline Q1:It's easy for me to find necessary information in this website & 1 & 2 & 3 & 4 & 5 & 6 & 7 \\
\hline Q2:I feel easy and smooth when I communicate with this website & 1 & 2 & 3 & 4 & 5 & 6 & 7 \\
\hline Q3: This website is easy to use & 1 & 2 & 3 & 4 & 5 & 6 & 7 \\
\hline Q4:When shopping on website, I'm satisfied with the customer service & 1 & 2 & 3 & 4 & 5 & 6 & 7 \\
\hline \multicolumn{8}{|l|}{ 2. Questions about Contents } \\
\hline Q5: The design of this website is attractive to me & 1 & 2 & 3 & 4 & 5 & 6 & 7 \\
\hline Q6: I can get the most accurate and up-to-date information in this website & 1 & 2 & 3 & 4 & 5 & 6 & 7 \\
\hline Q7: I think it's interesting when I visit this website & 1 & 2 & 3 & 4 & 5 & 6 & 7 \\
\hline
\end{tabular}


Table A1. Cont.

\begin{tabular}{|c|c|c|c|c|c|c|c|}
\hline \multirow[t]{2}{*}{ Questions } & \multicolumn{7}{|c|}{$\begin{array}{l}\text { Strongly Disagree } \\
\rightarrow \text { Strongly Agree }\end{array}$} \\
\hline & 1 & 2 & 3 & 4 & 5 & 6 & 7 \\
\hline \multicolumn{8}{|l|}{ 3. Questions about Commerce } \\
\hline Q8:The diverse custom-oriented activities on website is attractive to me & 1 & 2 & 3 & 4 & 5 & 6 & 7 \\
\hline Q9:Considered buying a promotional products (SALE or Group-buying) on the website & 1 & 2 & 3 & 4 & 5 & 6 & 7 \\
\hline Q10: I'd like to receive the coupon of this website & 1 & 2 & 3 & 4 & 5 & 6 & 7 \\
\hline Q11:The products in this website is price competitive & 1 & 2 & 3 & 4 & 5 & 6 & 7 \\
\hline \multicolumn{8}{|l|}{ 4. Questions about Community } \\
\hline Q12: I'd like to receive the recommendation by other users in this website & 1 & 2 & 3 & 4 & 5 & 6 & \\
\hline Q13:When I use this website, continual interaction with other members can give me a sense of belonging & 1 & 2 & 3 & 4 & 5 & 6 & \\
\hline Q14:The evaluation of products is objective in this website & 1 & 2 & 3 & 4 & 5 & 6 & \\
\hline Q15:I bought some products because other members gave highly evaluation or recommended to me or & 1 & 2 & 3 & 4 & 5 & 6 & \\
\hline \multicolumn{8}{|l|}{ 5. Questions about Initial Trust } \\
\hline Q16: I think this website is thinking about the interests of me, not just for earning money & 1 & 2 & 3 & 4 & 5 & 6 & \\
\hline Q17: I feel reliable when I buy products in this website & 1 & 2 & 3 & 4 & 5 & 6 & \\
\hline Q18: I believe this website will keep commitments to us & 1 & 2 & 3 & 4 & 5 & 6 & \\
\hline \multicolumn{8}{|l|}{ 6. Questions about Ongoing Trust } \\
\hline Q19: I trust this website because its brand strength & 1 & 2 & 3 & 4 & 5 & 6 & \\
\hline Q20: Based on my previous experience, I know this website is trustworthy & 1 & 2 & 3 & 4 & 5 & 6 & \\
\hline Q21: I believe this website is always well-meaning to us. & 1 & 2 & 3 & 4 & 5 & 6 & \\
\hline \multicolumn{8}{|l|}{ 7. Questions about Purchase Intention } \\
\hline Q22: I intend to continue using the website & 1 & 2 & 3 & 4 & 5 & 6 & \\
\hline Q23: It is likely that I will transact with this web retailer in 3 mouths & 1 & 2 & 3 & 4 & 5 & 6 & \\
\hline Q24: I predict that I should use this web site in the distant future & 1 & 2 & 3 & 4 & 5 & 6 & \\
\hline Q25: I tried others, but I still want to buy products in this website & 1 & 2 & 3 & 4 & 5 & 6 & \\
\hline
\end{tabular}

\section{References}

1. Ministry of Commerce of China. Available online: http://english.mofcom.gov.cn/article/ newsrelease/significantnews/201408/20140800682807.shtml (accessed on 1 April 2015).

2. E-commerce in ASIA, Statistics and Trends. Available online: http://www.go-globe.com/blog/ ecommerce-in-asia/ (accessed on 1 April 2015).

3. Doney, P.M.; Cannon, J.P.; Mullen, M.R. Understanding the influence of national culture on the development of trust. Acad. Manag. Rev. 1998, 23, 601-620.

4. Choi, Y.; Gao, D. The role of intermediation in the governance of sustainable Chinese web marketing. Sustainability 2014, 6, 4102-4118.

5. Gefen, D.; Straub, D.W. Consumer trust in B2C e-commerce and the importance of social presence: Experiments in e-Products and e-Services. Omega 2004, 32, 407-424.

6. Ganguly, B.; Dash, S.B.; Cyr, D. Website characteristics, Trust and purchase intention in online stores: An Empirical study in the Indian context. J. Inf. Sci. Technol. 2009, 6, 22-44.

7. Lu, Y.B.; Yu, J.H. An empirical study of the factors that can effect on customers initial trust in B2C. J. Nankai Bus. Rev. 2005, 8, 96-101. 
8. Lu, Y.B.; Zhou, T. A research of consumers' initial trust in online stores in China. J. Res. Pract. Inf. Technol. 2007, 39, 167-180.

9. Ou, C.X.J.; Davison, R.M.; Pavlou, P.A.; Li, M.Y. Leveraging rich communication tools: Evidence of online trust and Guanxi in China. In Proceedings of the ICIS 2008, Paris, France, 14-17 December 2008; p. 66.

10. Chen, Y.-H.; Barnes, S. Initial trust and online buyer behavior. Ind. Manag. Data Syst. 2007, 107, 21-36.

11. Surowiecki, J. The Wisdom of the Crowds: Why the Many Are Smarter than the Few and How Collective Wisdom Shapes Business, Economies, Societies and Nations; Doubleday: New York, NY, USA, 2004.

12. Zhu, L.; Benbasat, I.; Jiang, Z. Investigating the role of presence in collaborative online shopping. In Proceedings of the 12th Americas Conference on Information Systems (AMCIS), Acapulco, Mexico, 4-6 August 2006; p. 11.

13. Leitner, P.; Grechenig, T. Community driven commerce: Design of an integrated framework for social shopping. In Proceedings of the IADIS International Conference on e-Commerce, Algarve, Portugal, 10-11 December 2007; pp. 344-353.

14. Stephen, A.T.; Toubia, O. Deriving value from social commerce networks. J. Mark. Res. 2010, 47, 215-228.

15. Wang, C.; Zhang, P. The evolution of social commerce: The people, management, technology, and information dimensions. Commun. Assoc. Inf. Syst. 2012, 31, 105-127.

16. Choi, Y.; Zhang, N. Introduction to the Special Issue on "The Sustainable Asia Conference 2014". Sustainability 2015, 7, 1595-1602.

17. Dodds, W.B.; Monroe, K.B.; Grewal, D. Effects of price, brand and store information on buyers' product evaluations. J. Mark. Res. 1991, 28, 307-319.

18. Schiffman, L.G.; Leslie, L.K. Consumer Behavior, 7th ed.; Prentice Hall International Inc.: Madison, WI, USA, 2000.

19. Spears, N.; Singh, S.N. Measuring attitude toward the brand and purchase intentions. J. Curr. Issues Res. Advert. 2004, 26, 53-66.

20. Ganguly, A. The Art of Business Communication; Goodwill Publishing House: New Delhi, India, 2009.

21. Davison, R.M.; Ou, C.X.J. Guanxi, knowledge and online intermediaries in China. Chin. Manag. Stud. 2008, 2, 281-302.

22. Moorman, C.; Deshpande, R.; Zaltman, G. Relationships between providers and users of market research: The dynamics of trust within and between organizations. J. Mark. Res. 1992, 29, 314-325.

23. Koufaris, M.; Hampton-Sosa, W. The development of initial trust in an online company by new customers. Inf. Manag. 2004, 41, 377-397.

24. Choi, Y. A comparative study on the web marketing mix strategy of the global e-commerce meta-mediary. J. Korea Trade 2006, 8, 161-179.

25. Ranganathan, C.; Ganapathy, S. Key dimensions of business-to-customer websites. Inf. Manag. 2002, 39, 457-465.

26. Taylor, M.J.; England, D. Internet marketing: Web site navigational design issues. Mark. Intell. Plan. 2006, 24, 77-85. 
27. Mithas, S.; Jones, J.L. Do auction parameters affect buyer surplus in e-auctions for procurement? Prod. Oper. Manag. 2007, 16, 455-470.

28. Anckar, D. Valsystem i lilleputtar: Pluralitet och diffusion. Politiikka 2001, 44, 4-16. (In Swedish)

29. Joung, S.H.; Park, S.W.; Ko, Y.J. Willingness to pay for eco-friendly products: Case of cosmetics. ASIA Mark. J. 2014, 15, 33-49.

30. McMillan, D.W.; Chavis, D.M. Sense of community: A definition and theory. J. Community Psychol. 1986, 14, 6-23.

31. Pavlou, P.; Gefen, D. Building effective online marketplaces with institution-based trust. Inf. Syst. Res. 2004, 15, 37-59.

32. Jang, H.Y.; Jeong, K.H.; Jeong, D.Y. The consequences of customer trust and the determinants of purchasing intention in Internet shopping mall. J. MIS Res. 2005, 15, $23-49$.

33. Kuan, H.H.; Bock, G.W. Trust transference in brick and click retailers: An investigation of the before-online-visit phase. Inf. Manag. 2007, 44, 175-187.

34. Wong, Y.H.; Tam, J.H.L. Mapping relationships in China: Guanxi dynamic approach. J. Bus. Ind. Mark. 2000, 15, 57-70.

35. Hoehle, H.; Huff, S.; Goode, S. The role of continuous trust in information systems continuance. J. Comput. Inf. Syst. 2012, 52, 1-9.

36. Armstrong, S.J.; Overton, T.S. Estimating non-response bias in a mail survey. J. Mark. Res. 1977, 14, 396-402.

37. Yang, G. Effect of Website Characteristics under B2C Environment on Consumer Trust and Purchase Intention. Master's Thesis, Harbin Institute of Technology, Harbin, China, 2013.

38. Hussey, D.M.; Eagan, P.D. Using structural equation modeling to test environmental performance in small and medium-sized manufacturers: Can SEM help SMEs? J. Clean. Prod. 2007, 15, 303-312.

39. Khanna, M.; Speir, C. Motivations for proactive environmental management. Sustainability 2013, 5, 2664-2692.

40. Tapia-Fonllem, C.; Corral-Verdugo, V.; Fraijo-Sing, B.; Durón-Ramos, M. Assessing sustainable behavior and its correlates: A measure of pro-ecological, frugal, altruistic and equitable actions. Sustainability 2013, 5, 711-723.

41. Choi, Y.; Yu, Y. The influence of perceived corporate sustainability practices on employees and organizational performance. Sustainability 2014, 6, 348-364.

42. Campbell, D.T.; Fiske, D.W. Convergent and discriminant validation by the multitraitmultimethod matrix. Psychol. Bull. 1959, 56, 81-105.

43. Fornell, C.; Larcker, F.D. Evaluating structural equation models with unobservable variables and measurement error. J. Mark. Res. 1981, 18, 39-50.

44. Bagozzi, R.P.; Yi, Y. On the evaluation of structural equation models. J. Acad. Mark. Sci. 1988, 16, 74-93.

45. Baron, R.M.; Kenny, D.A. The moderator-mediator variable distinction in social psychological research: Conceptual, strategic, and statistical considerations. J. Pers. Soc. Psychol. 1986, 51, 1173-1182.

46. Chen, S.C.; Yen, D.; Hwang, M. Factors influencing the continuance intention to the usage of web 2.0: An empirical study. Comput. Hum. Behav. 2012, 28, 933-941.

47. Alibaba. What is Trustpass? Available online: http://img.alibaba.com/others/popup/ trust_030325.html (accessed on 1 April 2015). 
48. Choi, Y. Introduction to the special issue on "Sustainable E-Governance in Northeast Asia: Challenges for Sustainable Innovation”. Technol. Forecast. Soc. Change 2015, 96, 1-3.

(C) 2015 by the authors; licensee MDPI, Basel, Switzerland. This article is an open access article distributed under the terms and conditions of the Creative Commons Attribution license (http://creativecommons.org/licenses/by/4.0/). 